\title{
Research on Scientific Research Management in Secondary Schools of Higher Vocational Colleges
}

\author{
Jing LV \\ Xi'an Aeronautical Polytechnic Institute Office of Academic Research, Xi'an 710089, China. \\ xihang710089@163.com
}

Keywords: higher vocational college; the secondary schools; scientific research management; scientific research project.

\begin{abstract}
Based On The Scientific Research Management System Of The Sub-Academies Of Higher Vocational Colleges, then analysis research activities, head of the school, secondary school leadership, scientific research project, individual researchers and teachers colleges and universities scientific research management institutions different roles of responsibility and mission, and put forward the secondary school as the main body in the scientific research management, guided by the demands of development of key disciplines, to the scientific research management of scientific research project declaration for the gripper ideas, improve the level of scientific research management, to create a good scientific research environment.
\end{abstract}

\section{Introduction}

The ascending connotation, teaching and scientific research management of higher vocational education guide (ministry of education higher education department of the People's Republic of China The national vocational college principals association) said: "research occupies absolute important position in higher vocational colleges, teaching and scientific research of higher education exists between inner link, the main form of scientific research is not only for the social service in colleges and universities, and is to cultivate talents, improve the level of teachers, promote the professional development the important means. Teaching can further disseminate teachers' research results, and scientific research will also promote teaching. And the basic theory that the teacher grasps in teaching and the thought that the student is active also can promote the further development of scientific research work, teaching and scientific research are inseparable. In order to improve the teaching quality of education in higher vocational colleges, we should not only pay attention to the teaching work, but also pay more attention to the scientific research work and the management of teachers' scientific research work. Higher vocational education in order to promote the scientific and standardization of scientific management, improve the management level, should be based on the actual needs of school, school, hospital management mode, combining with the characteristics of higher vocational education, the analysis of what the role of various scientific research activities, to improve the level of scientific research management, to create the goal of scientific research management environment, can also improve college teaching quality, enhance service ability, the development of connotation construction.

\section{Research development strategy led by the institute (school)}

In higher vocational colleges that implement the management system of secondary colleges, whether the scientific research work can be carried out smoothly depends first of all on whether the university leaders have clear scientific research awareness and development strategy. The scientific research consciousness of higher vocational colleges is weaker than that of undergraduate colleges, which requires more attention and guidance from college leaders. "If university leaders can attach importance to scientific research and have the research mission and research strategy, higher vocational colleges can form a strong research atmosphere." It should be embodied in the following four aspects: 
(1) Provide scientific research support services and set up scientific research management institutions and scientific research project management institutions.

(2) Formulate scientific research policies and operating programs, such as teacher research compensation and award, teacher comprehensive development plan, establishment and operation of scientific research committee or academic committee, etc.

(3) Improve the guarantee of scientific research funds and experimental facilities, and obtain support from sexual policies, scientific research procedures, intellectual property policies and operational guidelines.

(4) Attach importance to scientific research. University leaders will take the lead in doing scientific research and actively participate in scientific research.

\section{Research Responsibilities of Secondary Colleges (Departments)}

To formulate scientific and effective measures for the administration of scientific research

Secondary school should set up scientific research secretary in the secondary school under the leadership of President in charge of scientific research, usually in the scientific research plan formulation and implementation, the scientific research outlay budget and internal research resource allocation and management, scientific management and maintenance of facilities and related areas, to provide good service for teachers to carry out scientific research activities. The research secretary will also provide quality management and supervision of the whole process of scientific research on behalf of the secondary school. Secondary school to support the scientific research of the teachers, in the scientific research project application review and approve the introduction of special talents, scientific research and employment, the establishment of the priority areas of scientific research, scientific research team building, visiting and academic conference funding, academic accreditation work of organization and management, the support of scientific research and cultural activities, the effective management of scientific research and scientific research activities of recurring expenses to undertake, etc., to provide a good scientific research environment. We should actively form interaction in and out of school scientific research and establish relatively stable cooperation and partnership. Surrounding the construction of key disciplines development direction, a high level of teaching and scientific research team, the subject development demand as the guidance, to establish "to promote teaching by scientific research and teaching support for scientific research", to solve the relationship between the teaching and scientific research.

(2) Take the declaration of scientific research projects as the focus to refine and implement scientific research tasks

Secondary school of scientific research work should be guided by the development and construction of key disciplines, scientific research project declaration as the gripper, detailed scientific research tasks, project planning and written declaration instruction, only in this way can effectively implement scientific research management. Research in higher vocational colleges should first campus project as the starting point of scientific research, and then encourage declare provincial department, provincial natural science fund project, province social science fund project of philosophy and social science GuiHuaBan SheKeLian major theoretical and practical issues of the research project, provincial department of education scientific research projects and the education teaching reform project, etc. When conditions are ripe, can also be elected some have hosted by Dr, professor of middle-aged and young scientific research project of research basis and research value, impact on the national natural science fund project and the declaration of national social science fund project.

\section{Clarify the Responsibilities of the Project Leader in Scientific Research}

Scientific research project director must have a team of scientific research way of thinking, pay attention to group collaboration and complementary discipline knowledge, found the scientific research of the construction of the interaction, cooperation and partnership, great importance to the 
development of scientific thought and scientific research environment. Such as group seminars, problem discussions, special reports, encouragement of participation in academic conferences or exchange visits, and electronic presentation through websites, etc. Comply with the scientific research quality management procedures and the daily management framework of scientific research projects. Play its leading role in the scientific research project application, and potential external donors and the scientific research support the leadership of the colleges and universities, so as to obtain the greatest possible funding and policy support. In the later period of scientific research, we should also take an active part in peer review and expert evaluation activities to promote the promotion and application of scientific research results.

\section{Strengthen the Role of Teachers as Individual Researchers in Scientific Research}

In colleges and universities, scientific research ability is an important embodiment of teachers' ability, even the highest embodiment of teachers' ability. Teachers in higher vocational colleges must combine their own specialty and work to determine personal development planning and research career strategy. We should cultivate our own scientific research thought and ability, integrate into the scientific research environment of the university, and make contributions to the construction and development of the important disciplines of the university with our own scientific research. Attach importance to and abide by the quality management of scientific research in the process of scientific research, make reasonable use of other forms of knowledge, and actively keep necessary contact and communication with project leaders and college leaders. Using the understanding of the discipline, and actively contributed to the popularization and application of scientific research achievements, a multidisciplinary multi-level contacts and research partnerships, the ultimate goal is to achieve a specific research project tasks, and the application of scientific research to teaching practice. As the main body of teaching organization and management, secondary institutions should arouse every teacher's enthusiasm for scientific research and give full play to their initiative in scientific research. In the initial stage of scientific research, more mobilization is needed from the individual development of researchers.

\section{Responsibilities of Scientific Research Management Institutions}

As management of higher vocational college scientific research management organization, need to strengthen the scientific research management and service consciousness, innovative scientific research management and operation mechanism, for teachers to provide a scientific and positive research environment. "Renewing the scientific research management concept is the primary problem faced by universities at present, and the basis of the scientific research innovation system is the change of ideas" [5]. Successful scientific research management can promote the implementation of scientific research and the formation of good scientific research environment. There are three common incentive theories in scientific research management:

(1) Hertzberg's two-factor theory: this theory believes that there are two types of factors influencing motivation, namely "health care factor" and "incentive factor". The motivation factor refers to the internal factor, which is a kind of satisfaction (interest in work, responsibility) from the job itself. Health care factors refer to external factors, i.e. factors other than work (remuneration, working environment). The two-factor theory is similar to Maslow's hierarchy of needs theory. Motivation factors are equivalent to the need for respect, the need for self-actualization and other higher needs.

(2) The equity theory of Adams: the theory is that an individual's sense of fairness is a kind of subjective feeling, and is compared with others does not depend on the absolute value of the reward treatment, and depends on the comparison of relative value. People are very sensitive to whether they are treated fairly and reasonably, and the sense of fairness has a great impact on motivation. 
(3) Skinner's reinforcement theory: the theory is that all forms of praise, reward, promotion belongs to positive reinforcement, various forms of criticism, punishment for negative reinforcement, incentive mechanism must be good at use rewards and punishment in the two kinds of means.

Using incentive theory inspire positive factors and the positive reinforcement of direct material reward is an abecedarian only, is also a must, but more important is to carry on the guidance of publicity and guidance, to reasonable use all kinds of incentive mechanism, constructing scientific and effective incentive system. Common scientific incentive system in higher vocational colleges are: the scientific research work of quantitative evaluation measures for the administration of the school (courtyard) employment post appointment for teaching and scientific research management measures for the teaching and research work management workload calculation method "the post performance salary standard for teaching and scientific research of the senior professional technical position, highly educated high degree special allowance method" and so on. Clear scientific research motivation, reward system, to make scientific research environment of scientific research management of China's universities to have a clear understanding with the target, eventually make every teachers tend to engage in scientific research activities, systematic, targeted to rush.

\section{Conclusion}

With the continuous improvement of the scientific research strength of secondary colleges of higher vocational colleges and the further promotion of the management mode of scientific research two levels, the future scientific research management will face more complex situations and challenges. Secondary school in the management of scientific research, only by constantly seeking innovation, adapt to the requirement of times development, using modern management methods, to speed up the school scientific research development, improve the level of school of scientific research to make due contributions.

\section{Acknowledgments}

Project grant of research project of education department of Shanxi province (project no. : 17JK0399).

\section{References}

[1]. Zhang Aihua. Implementation of and inspiration from undergraduate scientific research training programs in domestic and foreign research universities [J]. Science \& Technology Information, 2007 (24): 109-109.

[2]. Jiang Yin. Research on different impacts of scientific research training activities on college students' ability to innovate [J]. Academic Journal of Changchun University of Technology (Higher Education Research Edition), 2010, 31(2): 31-33.

[3]. Bai Wenyuan, Zhang Wenzheng. Exploration on management modes of college student scientific research training programs [J]. Research in Teaching, 2010 (4): 99-102.

[4]. Bie Jun, Wei Xiaowei. Encouraging college students to actively participate in scientific research and cultivate high-quality innovative talents [J]. Research on Higher Education, 2011, 28 (2): 85-91. 